\title{
Microstructure Evolution of Ni-base Superalloy 625: from Conventional Thermomechanical Processed to Selective Laser Melting Processed
}

\author{
C. Labre ${ }^{1,2}$, A.L. Pinto ${ }^{1}$ and I.G. Solórzano ${ }^{2}$ \\ 1. Brazilian Center of Research in Physics (CBPF), Rio de Janeiro, Brazil \\ 2. Department of Chemical and Materials Engineering, PUC-Rio, Rio de Janeiro, Brazil
}

Additive manufacturing (AM) is a layer-by-layer fabrication for building three-dimensional objects. This technique is based on a selective fusing and consolidating thin layers of loose powders with a scanning laser beam [1]. Among the various methods of additive manufacturing, the selective laser melting (SLM) technique has proved progress in recent years as an alternative manufacturing route to produce complex shaped metallic objects. A number of alloy systems are recently reported to be processed by AM but little is known about Ni-base super alloys.

Here it is reported the investigation on an AM produced Alloy 625 sample. Alloy 625 is a solidsolution and precipitation strengthened nickel-base superalloy $(\mathrm{Cr} 21,29 \mathrm{wt} \%, \mathrm{Mn} \mathrm{0,20wt} \%$, C 0,015wt\%, Si 0,17wt\%, Mo 8,77wt\%, Ti 0,14wt\%, Al 0,18 wt \%, Nb 3,67wt\%, Fe 3,05wt\% and Ni (bal.)). This alloy is extensively used in industrial applications that require a combination of excellent creep and high corrosion resistance at temperatures below $800{ }^{\circ} \mathrm{C}$ [2]. This investigation focused on the microstructural evolution of alloy 625 in different steps from an as-received bulk sample (solution treated and aged at $700{ }^{\circ} \mathrm{C}$ ), a 625 alloy powder and a SLM consolidated sample. Details of the processing are reported by others [2]. A FEG SEM operating in conventional, analytical and EBSD modes (JEOL 7100F) was used for overall characterization. Samples of a SLM produced object were sectioned, polished by conventional mechanical methods and electrolytically etched with a

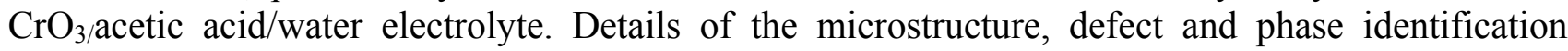
required analytical STEM, diffraction and phase contrast TEM (JEOL 2100F). While TEM thin foils from the bulk alloy were produced by sectioning and double jet electrolytic thinning, TEM samples from powder alloy and from the SLM sample was FIB prepared.

In Figure 1, EBSD imaging, it is shown the equiaxial grain structure of both bulk and powder alloy 625 although with different grain size, as expected. Figure 2, shows typical substructure of as received bulk alloy containing typical defects such as geometrical necessary dislocation carbide precipitates (Figure 2a) and also a fine dispersion of $\gamma^{\prime \prime}$ phase. This dispersion is also observed in the powder grain sample (Figure 2b). After SLM processing a dramatic transformation of the overall microstructure is clear, as shown in the 3D SEM image composition of Figure 3A, where the formation of coarsen carbides is prominent. The morphology and alignment of such carbides are columnar arrays in the growth direction. In Figure 3b and 3C, elemental EDS mapping of selected individual carbides are presented and described in the caption [3].

\section{References:}

[1] Y.J. Zhang et al, J. Alloy Comp. 570 (2013), p. 70.

[2] J. Hernandez et al, Journal of Materials Science Research 1 (2012), p. 124.

[3] The authors are grateful to CBPF for providing full access to the LABNANO Electron

Microcopy facilities and to the Brazilian Funding agencies CNPq, FINEP and FAPERJ. 


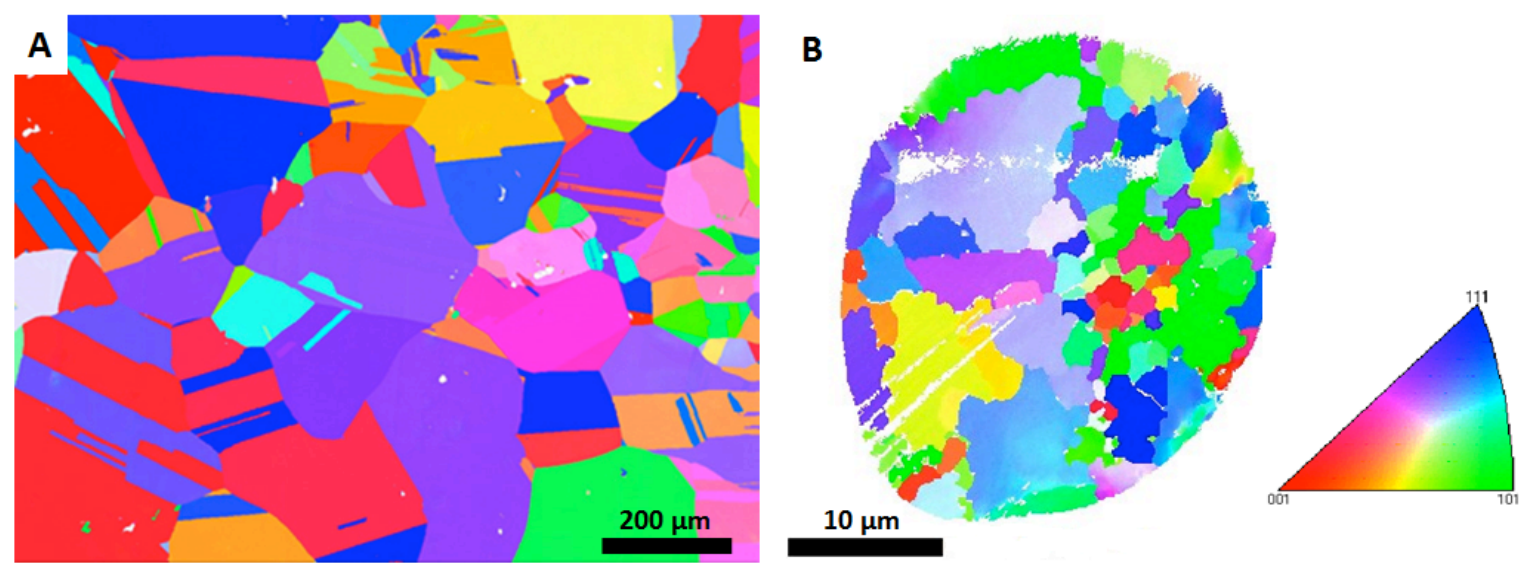

Figure 1. EBSD Map of as-received Alloy 625 (A) bulk and (B) powder: Grains are equiaxial but different size.
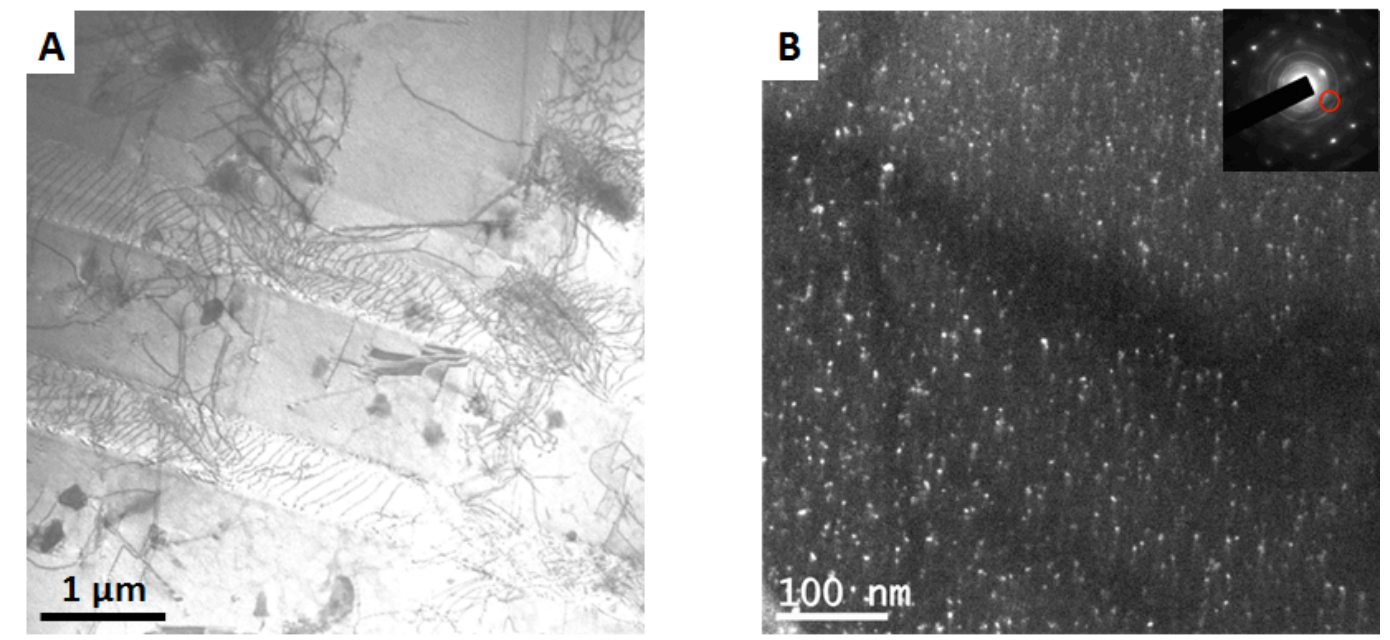

Figure 2. Typical microstructure of bulk a 625 with carbides and defects (A) and $\gamma^{\prime \prime}$ phase fine recipitation and (B) dark field image of $\gamma^{\prime \prime}$ obtained from powder sample.

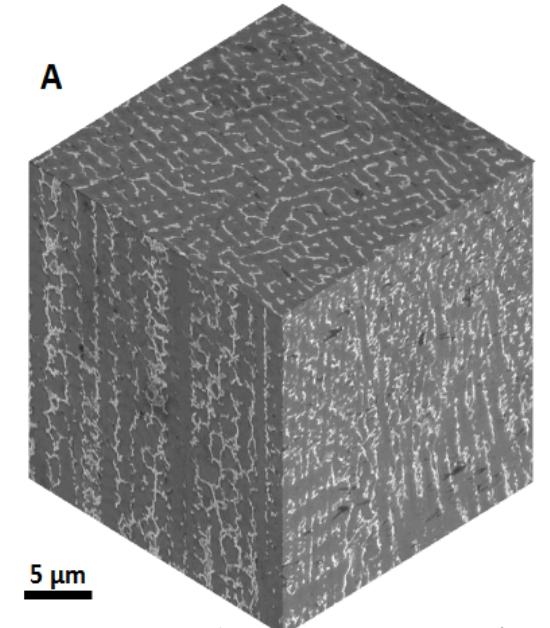

Figure 3. A) - 3D SEM image composition for a SLM fabricated Alloy 625 component, showing carbide alignment. B) SEM image and EDS elemental mapping of an individual complex carbide containing $\mathrm{Ni}, \mathrm{Cr}$, Mo and $\mathrm{Nb}$. C) Carbide aggregate with different morphologies and partitioning of $\mathrm{Mo}$ and $\mathrm{Nb}$ but depleted of $\mathrm{Ni}$ and $\mathrm{Cr}$.

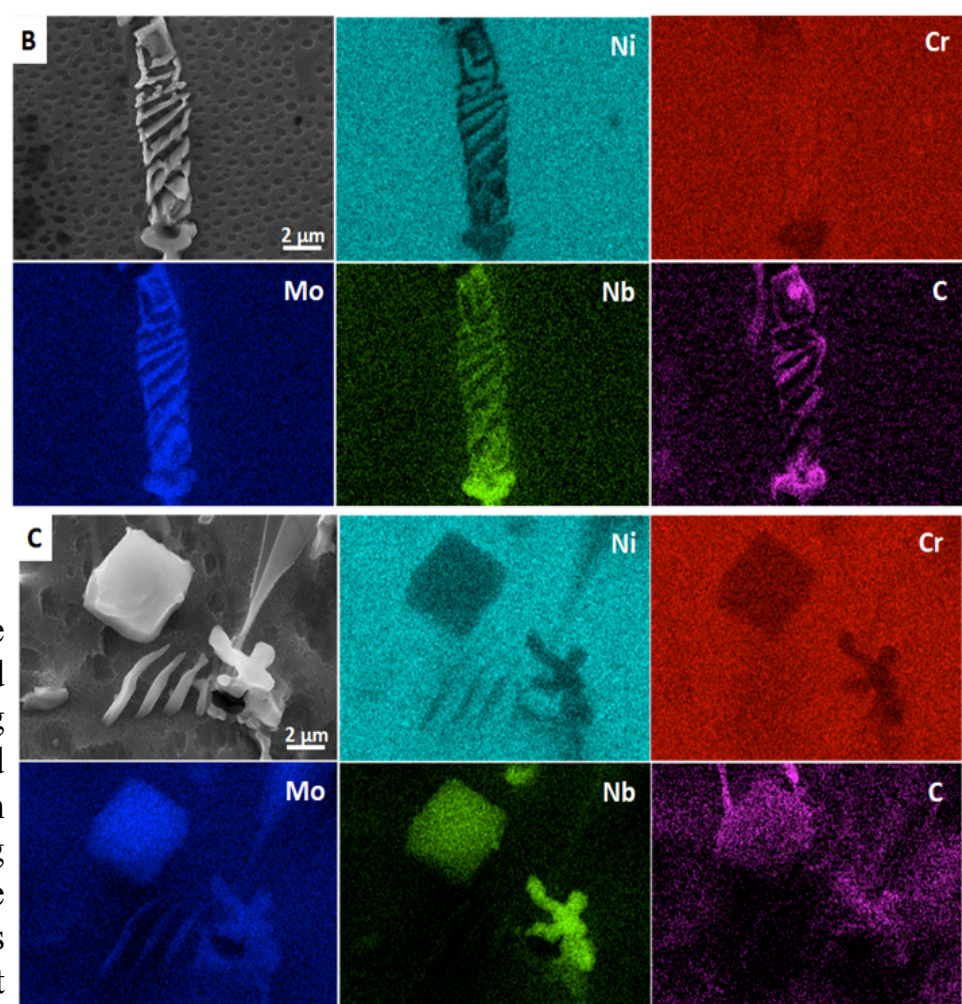

